\title{
ERRATA
}

To the paper

\section{Determination of lanthanides and other trace elements in ferns by instrumental neutron activation analyis}

\author{
T. Ozaki, ${ }^{*}$ S. Enomoto, $* *$ Y. Minai, $*$ S. Ambe, $* *$ F. Ambe,** T. Tominaga* \\ * Department of Chemistry, School of Science, The University of Tokyo, Hongo, Tokyo 113, Japan \\ ** The Institute of Physical and Chemical Research (RIKEN), Wako, Saitama 351-01, Japan
}

appeared in the Journal of Radioanalytical and Nuclear Chemistry, Vol. 217, No. 1. (1997) 117-124. On page 121, the correct "Fig. 3. Histogram of La ion fern samples" is as follows:

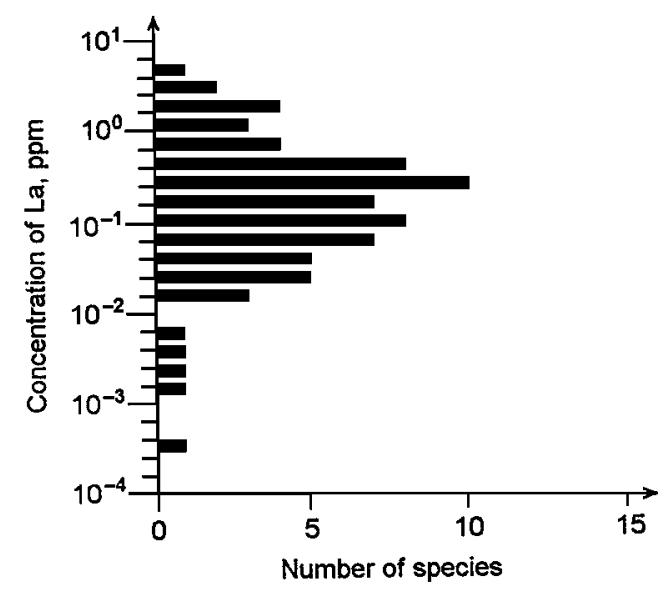

To the paper

\section{Enhancement of phenols on ion-pair extraction of chromium(VI) with tetraphenylarsonium

\author{
S. Katsuta,* N. Suzuki \\ * Department of Chemistry, Faculty of Science, Tohoku University, Sendai 980-77, Japan
}

appeared in Journal of Radioanalytical and Nuclear Chemistry, Vol. 222, Nos 1-2 (1997) 45-50. On page 45 the title of the paper should read "Enhancement effect of phenols on ion-pair extraction of chromium(VI) with tetraphenylarsonium". 